\title{
Analysis of Transient Belt Stretch for Horizontal and Inclined Belt Conveyor System
}

\author{
Sanjay G. Sakharwade \\ Department of Mechanical Engineering \\ Bhiali Institute of Technology, Durg, India \\ Corresponding author: sanjaysakharwade@gmail.com \\ Shubharata Nagpal \\ Department of Mechanical Engineering \\ Bhiali Institute of Technology, Durg, India
}

(Received March 23, 2019; Accepted June 9, 2019)

\begin{abstract}
Belt is costliest part of belt conveyor system. Sudden rise in belt tension within transient starting condition, results in belt failure and structure damage. It is difficult to measure these stresses by static calculation method and hence their presence might go undetected. Belt elongation is an evident quantity for these stresses. Dynamic belt stretch is formulated in terms of displacement response of conjugative belt units with respect to time. This paper presents analysis of the event and propagation of dynamic belt stretch for straight horizontal and straight inclined belt conveyor system. Dynamic behavior of belt system is investigated for starting condition of fully stacked conveyor belt. Belt conveyor system is considered as series of vibrating mass and its unit is assumed to be a viscoelastic segment. Equation of motion of belt unit is developed by Lagrange's approach. Observed transient parameters are more vibrant in inclined belt than the horizontal belt system. Maximum value of dynamic belt stretch for horizontal belt systems founds $1.13 \%$ of total belt length and for inclined belt conveyor system, it is $1.16 \%$ of belt length. Both values are within range of standard value specified for fabric belt system.
\end{abstract}

Keywords- Transient, Stretch, Belt conveyor, Simulation, Lagrange.

\section{Introduction}

Belt conveyor is most preferred bulk material transfer system. It is employed in vast industries like mine, metal, power, food etc. For a specified use belt conveyor system design relies on static calculation methodology and belt is selecting on the basis of maximum tension occurred during running. Designer uses 8 to 10 factor of safety for belt choice (DIN 2011; Yang, 2014). Conveyor belt is most significant element and accounted 30\%-50\% of the overall conveyor system cost (CEMA, 1997). It is a key component of belt conveyor and affects overall performance of the entire system. During operation, endless conveyor belt suffers varying tension at the different station which results corresponding amount of belts stretch at particular belt segment. Starting of system at fully loaded belt becomes a worse condition for the belt because maximum belt stretch occurs at this stage. This undue condition occurs during re-starting of system after any break down or power failure while in operation. According to conveyor belt manual, (Dunlop, 2016) fabric belt has maximum $2.0 \%$ elongation during operation and this value is recommended for deciding stroke length of the take-up pulley.

Conveyor belt composed of a tension bearing carcass material and its protective rubber cover. In fabric belts carcass is a woven structure of polymers. Polymer and rubber mutually exhibits property of creep, hysteresis, relaxation which shows its viscoelastic conduct (Pang et al., 2015; 
International Journal of Mathematical, Engineering and Management Sciences

Vol. 4, No. 5, 1169-1179, 2019

https://dx.doi.org/10.33889/IJMEMS.2019.4.5-092

Alzoubi et al., 2016). In large capacity and long distance conveyor dynamic characteristics plays very important role and emphasis to study accordance. Nordell and Ciozda (1984), Kim (1995), Harrison (1998) and Lodewijks (1996) initially worked on the dynamics of belt conveyor and found improved results than the static design method. Harrison, (2008) suggested a hybrid friction models with belt rubber losses and material flexing included in the initial tension calculations prior to any dynamic analysis. Hou and Meng, (2008) experimentally found that speed of stress wave increases nonlinearly with an increase in tension and concluded that vibration characteristics of a belt are mainly influenced by elastic properties of its material. Dynamic parameters of belt invariably vary throughout starting period (Karolewski and Ligocki, 2014) and many times belt failure occurs during such condition. Authors also worked extensively on Modeling of induction motor with electromagnetic moment formula to run simulation and suggest that there is a possibility to assume an arbitrary shape of the start-up ramp in the program. For transient analysis of conveyor operation, Kulinowski (2014), Li and Pang (2018) found that use of Kelvin-Voigt model during simulation tests is sufficient. Yang (2014) was formulated the equation of motion for belt conveyor based on the energy associated with conveyor belt and concluded with reduction of manufacturing cost by dynamic performance optimization. From past literature conveyor dynamics it is found that work on dynamic belt elongation is missing so far. Transient behavior of belt stretch for worse condition of full load starting would help to evaluate accurate stroke length of take-up pulley and also give realistic value of belt tension.

In this paper, series of viscoelastic model is used for conveyor belt system and dynamic properties are analyzed by simulation method. The work begins with static analytical method for design. In methodology section, belt model is developed with help of lump mass method. Each unit was investigated for its equivalent mass, frictional and inertial resistance considering the devices and system part associated with it (Leamy and Wasfy, 2002). Equation of motion of unit is developed by Lagrange's approach. Equations of motion for belt element lump mass are collectively developed and their model built in Simulink. Transient condition of belt conveyor is analyzed by simulating model considering thereof initial conditions (Hu et al., 2010). Dynamic parameters of the system i.e. velocity and displacement analyzed during transient starting. Dynamic belt stretch is studied in terms of dislocation in the conjugative units of the system. The simulated result studied for two cases of belt conveyor for different geometrical profile and conveying bulk material. It is found that maximum stretch in the belt during the starting process shows closed agreement with standards value of maximum elongation for the chosen belt length.

\section{Belt Conveyor Design}

Belt conveyor system design need to find out power requirement to transport material on belt. This power is to overcome friction resistance and to increase the potential energy of the material. The main resistance includes conveyor belt flexure resistance, bulk solid flexure resistance, rotational resistance of idlers and belt indentation rolling resistance (Woodcock and Mason, 2012). Thus, equation (1) represents total tractive pull required at drive pulley for steady state condition to run the belt conveyor system (Mulani, 2012).

$$
\mathrm{P}=\mathrm{CfgL}_{\mathrm{h}}\left(\mathrm{m}_{\mathrm{c}}+\mathrm{m}_{\mathrm{r}}+\mathrm{m}_{\mathrm{m}}+2 \mathrm{~m}_{\mathrm{b}}\right)+\mathrm{m}_{\mathrm{m}} \mathrm{H}_{\mathrm{m}} \mathrm{g}
$$

where,

$\mathrm{C} \quad=$ Conveyor length coefficient (.)

$\mathrm{f} \quad=$ Conveying friction coefficient (.)

$\mathrm{L}_{\mathrm{h}} \quad=$ Belt Horizontal run distance $(\mathrm{m})$ 
International Journal of Mathematical, Engineering and Management Sciences

Vol. 4, No. 5, 1169-1179, 2019

https://dx.doi.org/10.33889/IJMEMS.2019.4.5-092

$\mathrm{m}_{\mathrm{c}} \quad=$ Carrying idler rotating mass $(\mathrm{kg} / \mathrm{m})$

$\mathrm{m}_{\mathrm{r}} \quad=$ Return idler rotating mass $(\mathrm{kg} / \mathrm{m})$

$\mathrm{m}_{\mathrm{m}} \quad=$ Bulk material mass $(\mathrm{kg} / \mathrm{m})$

$\mathrm{H}_{\mathrm{m}} \quad=$ Total vertical lift of belt conveyor $(\mathrm{m})$.

Total conveying mass consist of belt, bulk mass and equivalent mass of rotating rollers and pulley. Idler linear inertial mass is taken 0.9 of their masses. Snub pulley masses acts $3 \%$ to $2 \%$ of total mass of system exclusive of drive unit mass, on transport and return side of belt respectively. Drive unit plus drive pulley adds $7.5 \%$ to $17.5 \%$ of previously calculated total mass; percentage deviation based on the lift of belt conveyor structure (Mulani, 2012). Total equivalent mass is used for reckoning of starting acceleration for the conveyor system to attain desired velocity. A force larger than effective pull is required to accelerate the inertial system. Taking into account generated stresses developed in the belt and safety of drive motor, staring pull is requiring being optimum (BIS IS 11592, 2010).

\section{Methodology}

For belt conveyor system, it not sole static characteristics, but also examination of complex dynamic characteristics for the start-up required. Polyester-Nylon (EP) belt are mostly use for conveying system (Manjgo et al., 2018), as EP belts are out there in wide range of tension capability. From viscoelasticity theory, conveyor belt can be modeled as more number of spring and damper through series or parallel, which reveals more near and real mechanical properties of the material (Lakes, 2009). Springs correspond to a flexible linear part with restorative forces and damper represents a viscous linear element with damping forces. Spring and a dashpot in parallel arrangement (Figure 1) yield the Kelvin- Voigt model. Kelvin- Voigt model is applied to analyze instant transient state of EP belt during process.

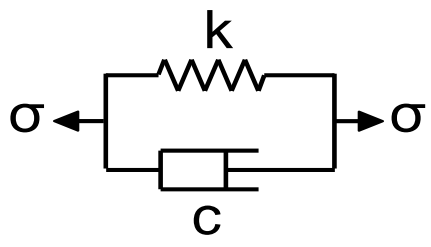

Figure 1. Kelvin-Voigt Model

\subsection{Lagrange's Approach}

Belt is running over the idlers and wrapping over various pulleys, like drive, tail pulley and takeup pulley. Belt possesses more loads on the carrying side than return side. The overall geometry of the system represents that belt experience various parametric quantity at different stations. For the analysis, the belt is divided in number of viscoelastic units adjoining in series. Figure 2 represent a belt unit model whose equation of motion is derived by Lagrange's approach. 
International Journal of Mathematical, Engineering and Management Sciences

Vol. 4, No. 5, 1169-1179, 2019

https://dx.doi.org/10.33889/IJMEMS.2019.4.5-092

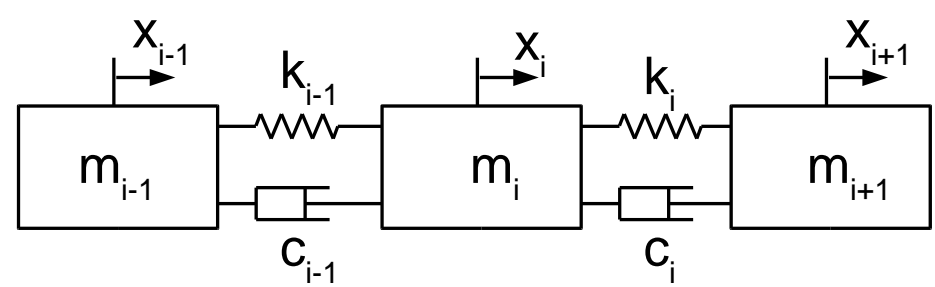

Figure 2. Belt unit model

Equivalents mass, stiffness and damping coefficient of i-th belt unit are represented by $\mathrm{m}_{\mathrm{i}}, \mathrm{k}_{\mathrm{i}}$ and $\mathrm{c}_{\mathrm{i}}$ respectively. For the belt unit model Kinetic energy $\mathrm{K}_{\mathrm{e}}$, potential energy $\mathrm{V}_{\mathrm{e}}$ and dissipation energy $\mathrm{D}_{\mathrm{e}}$, are defined by

$\mathrm{K}_{\mathrm{e}}=\frac{1}{2} \mathrm{~m}_{\mathrm{i}-1} \dot{\mathrm{x}}_{\mathrm{i}-1}^{2}+\frac{1}{2} \mathrm{~m}_{\mathrm{i}} \dot{\mathrm{x}}_{\mathrm{i}}^{2}+\frac{1}{2} \mathrm{~m}_{\mathrm{i}+1} \dot{\mathrm{x}}_{\mathrm{i}+1}^{2}$

$\mathrm{V}_{\mathrm{e}}=\frac{1}{2} \mathrm{k}_{\mathrm{i}-1}\left(\mathrm{x}_{\mathrm{i}}-\mathrm{x}_{\mathrm{i}-1}\right)^{2}+\frac{1}{2} \mathrm{k}_{\mathrm{i}}\left(\mathrm{x}_{\mathrm{i}+1}-\mathrm{x}_{\mathrm{i}}\right)^{2}$

$D_{e}=\frac{1}{2} c_{i-1}\left(\dot{x}_{i}-\dot{x}_{i-1}\right)^{2}+\frac{1}{2} c_{i}\left(\dot{x}_{i+1}-\dot{x}_{i}\right)^{2}$

where, $\mathrm{x}_{\mathrm{i}}$ is displacement of $\mathrm{i}$-th unit and $\dot{\mathrm{x}}_{\mathrm{i}}$ represents its velocity. More practical Lagrange equation (Jazar, 2013) is used for small linear vibrations of belt unit, is given by

$\frac{\mathrm{d}}{\mathrm{dt}}\left(\frac{\partial \mathrm{K}_{\mathrm{e}}}{\partial \dot{\mathrm{q}}_{\mathrm{l}}}\right)-\frac{\partial \mathrm{K}_{\mathrm{e}}}{\partial \mathrm{q}_{\mathrm{i}}}+\frac{\partial \mathrm{V}_{\mathrm{e}}}{\partial \mathrm{q}_{\mathrm{i}}}+\frac{\partial \mathrm{D}_{\mathrm{e}}}{\partial \dot{\mathrm{q}}_{\mathrm{l}}}=\mathrm{Q}_{\mathrm{i}}$

Where, $Q_{\mathrm{i}}$ is applied force on i-th unit consisting of external applied force and resistance force of the belt unit, both opposing nature. Partial derivatives of equation (2) carried out and substituted in the Lagrange equation (3),

Solving,

$\frac{\mathrm{d}}{\mathrm{dt}}\left(\frac{\partial \mathrm{K}_{\mathrm{e}}}{\partial \dot{\mathrm{q}}_{\mathrm{l}}}\right) \approx \frac{\mathrm{d}}{\mathrm{dt}}\left(\frac{\partial \mathrm{K}_{\mathrm{e}}}{\partial \dot{\mathrm{x}}_{\mathrm{i}}}\right)=\frac{\mathrm{d}}{\mathrm{dt}}\left(\mathrm{m}_{\mathrm{i}} \dot{\mathrm{x}}_{\mathrm{i}}\right)=\mathrm{m}_{\mathrm{i}} \ddot{\mathrm{x}}_{\mathrm{i}}$

$\frac{\partial \mathrm{K}_{\mathrm{e}}}{\partial \mathrm{q}_{\mathrm{i}}} \approx \frac{\partial \mathrm{K}_{\mathrm{e}}}{\partial \mathrm{x}_{\mathrm{i}}}=0$

$\frac{\partial \mathrm{v}_{\mathrm{e}}}{\partial \mathrm{q}_{\mathrm{i}}} \approx \frac{\partial \mathrm{v}_{\mathrm{e}}}{\partial \mathrm{x}_{\mathrm{i}}}=-\mathrm{k}_{\mathrm{i}-1} \mathrm{x}_{\mathrm{i}-1}+\left(\mathrm{k}_{\mathrm{i}-1}+\mathrm{k}_{\mathrm{i}}\right) \mathrm{x}_{\mathrm{i}}-\mathrm{k}_{\mathrm{i}} \mathrm{x}_{\mathrm{i}+1}$

$\frac{\partial \mathrm{D}_{\mathrm{e}}}{\partial \dot{\mathrm{q}}_{1}} \approx \frac{\partial \mathrm{D}_{\mathrm{e}}}{\partial \dot{\mathrm{x}}_{\mathrm{i}}}=-\mathrm{c}_{\mathrm{i}-1} \dot{\mathrm{x}}_{\mathrm{i}-1}+\left(\mathrm{c}_{\mathrm{i}-1}+\mathrm{c}_{\mathrm{i}}\right) \dot{\mathrm{x}}_{\mathrm{i}}-\mathrm{c}_{\mathrm{i}} \dot{\mathrm{x}}_{\mathrm{i}+1}$

Adding above four equations (a), (b), (c) and (d) obtaining differential equation of second order is equation of motion for $\mathrm{i}$-th unit, is given by

$\mathrm{m}_{\mathrm{i}} \ddot{\mathrm{x}}_{\mathrm{i}}-\mathrm{k}_{\mathrm{i}-1} \mathrm{x}_{\mathrm{i}-1}+\left(\mathrm{k}_{\mathrm{i}-1}+\mathrm{k}_{\mathrm{i}}\right) \mathrm{x}_{\mathrm{i}}-\mathrm{k}_{\mathrm{i}} \mathrm{x}_{\mathrm{i}+1}-\mathrm{c}_{\mathrm{i}-1} \dot{\mathrm{x}}_{\mathrm{i}-1}+\left(\mathrm{c}_{\mathrm{i}-1}+\mathrm{c}_{\mathrm{i}}\right) \dot{\mathrm{x}}_{\mathrm{i}}-\mathrm{c}_{\mathrm{i}} \dot{\mathrm{x}}_{\mathrm{i}+1}=\mathrm{Q}_{\mathrm{i}}$ 
International Journal of Mathematical, Engineering and Management Sciences

Vol. 4, No. 5, 1169-1179, 2019

https://dx.doi.org/10.33889/IJMEMS.2019.4.5-092

Resistance to belt motion along a given section of the conveyor is represented by $\mathrm{w}_{\mathrm{i}}$ and it is assumed that the value and the sense of the resistance force depend on the belt speed $\dot{x}_{i}$ (Song et al., 2006). Thus suffered resistance treated as extra damping for the unit and modified equation of motion, is given by

$\mathrm{m}_{\mathrm{i}} \ddot{\mathrm{x}}_{\mathrm{i}}+\left(\mathrm{c}_{\mathrm{i}}+\mathrm{c}_{\mathrm{i}-1}+\mathrm{w}_{\mathrm{i}}\right) \dot{\mathrm{x}}_{\mathrm{i}}-\mathrm{c}_{\mathrm{i}} \dot{\mathrm{x}}_{\mathrm{i}+1}-\mathrm{c}_{\mathrm{i}-1} \dot{\mathrm{x}}_{\mathrm{i}-1}+\left(\mathrm{k}_{\mathrm{i}}+\mathrm{k}_{\mathrm{i}-1}\right) \mathrm{x}_{\mathrm{i}}-\mathrm{k}_{\mathrm{i}} \mathrm{x}_{\mathrm{i}+1}-\mathrm{k}_{\mathrm{i}-1} \mathrm{x}_{\mathrm{i}-1}=\mathrm{F}_{\mathrm{i}}(\mathrm{t})$

Where $F_{i}(t)$ is external force acting on $i$-th unit. Belt conveyor system is modelled as five degree of freedom vibratory system. Two lump mass units well thought out on carrying side and three on return side. Figure 3 represents the temporal order of units taken in opposite direction of motion of the belt. Length of units is considered based on geometrical profile of belt the conveyor system. Equivalent mass, frictional and inertial resistance for each unit is calculated independently based on devices and system part allied with it. Take up mass is added equally to its neighboring units. Stiffness constant $\mathrm{k}_{\mathrm{i}}$ of each element is based on Young's modulus of carcase material and length of unit. Damping constant $c_{i}$ of each element consider as dependant value of element mass and stiffness assuming 0.1 hysteretic damping constant (Rao, 2007). Equation of motion for each unit is established with help of Lagrange method.

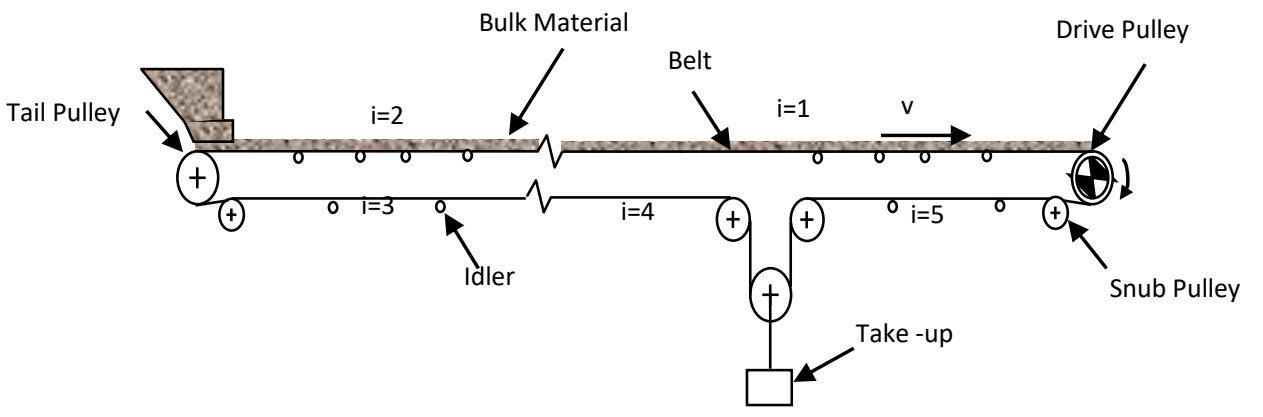

Figure 3. Conveyor belt system

\subsection{Belt Stretch}

Tractive pull applied to drive pulley, which pull loaded belt on carrying side causes dislocation in the belt mass. Displacement variation in each belt units with respect to time gives rise stretch in the belt segment. Moreover, magnitude of belt stretch is location dependent. Stretch in the belt is also time dependent and its magnitude is severe at initial phase of system booting. Maximum stretch occurs near head pulley on carrying side, as it is a driving force end. Return side is slack side of belt where mainly accumulation of belt occurs in between take-up and drive pulley exit end. This contraction helps to lower down the overall stretch in the endless conveyor belt over a period of steady state cyclic running. For the short period of transient condition, this contraction is neglected. Total stretch in the belt is formulated in terms of time dependent displacement, is given by

$\mathrm{Y}(\mathrm{t})=\sum_{\mathrm{i}=1}^{\mathrm{n}-1}\left[\mathrm{x}_{\mathrm{i}}(\mathrm{t})-\mathrm{x}_{\mathrm{i}+1}(\mathrm{t})\right]$ 
International Journal of Mathematical, Engineering and Management Sciences

Vol. 4, No. 5, 1169-1179, 2019

https://dx.doi.org/10.33889/IJMEMS.2019.4.5-092

\section{Simulation of Model}

Two different belt conveyors are studied for the dynamic characteristics of belt; one as straight horizontal conveyor and other having straight inclined profile. Each conveying system have single drive pulley at head end and EP belt is selected for bulk conveying. First conveying system is used to convey iron ore and second system is used for phosphate rock transportation. Based on maximum belt tension and factor of safety, EP1250/3 and EP800/4 belt are being selected respectively. Capacity, bulk material conveyed and length of conveying are different for both. Table 1 enlists geometrical and material parameters of both conveyor belt systems. Equations of motion for five belt element lump mass for each conveying system are developed and then their united model built in Simulink. For continuous lump parameter model; when $i=1, x_{i-1}=x_{n}$ and $\mathrm{i}=\mathrm{n}, \mathrm{x}_{\mathrm{i}+1}=\mathrm{x}_{1}$. Transient condition of belt conveyor is evaluated by simulating model taking into consideration the initial conditions as, $t=0, x_{i}=0, \dot{x}_{i}=0$. Conveyor belt dynamics is simulated for fully loaded starting condition. 1.45 times higher staring tractive pull applied at drive pulley circumference is taken as input to run the simulation. A ramp function is used between starting pull and steady state pull, over a time period, till attaining steady state velocity of the entire belt system.

Table 1. Specifications of belt conveyor system

\begin{tabular}{|c|l|c|c|}
\hline $\begin{array}{c}\text { Sr. } \\
\text { No. }\end{array}$ & Particulars & & \\
\hline 1 & Horizontal length of conveyor & $731.52 \mathrm{~m}$ & $609.2 \mathrm{~m}$ \\
\hline 2 & Lift of conveyor & - & $22.86 \mathrm{~m}$ \\
\hline 3 & Diameter of drive pulley & $1.07 \mathrm{~m}$ & $0.63 \mathrm{~m}$ \\
\hline 4 & Diameter of tail pulley & $1.07 \mathrm{~m}$ & $0.5 \mathrm{~m}$ \\
\hline 5 & Spacing of carrying idler & $0.915 \mathrm{~m}$ & $3.05 \mathrm{~m}$ \\
\hline 6 & Spacing of return idler & $3.05 \mathrm{~m}$ & $1.2192 \mathrm{~m}$ \\
\hline 7 & Width of belt & $1.2192 \mathrm{~m}$ & $0.0133 \mathrm{~m}$ \\
\hline 8 & Thickness of belt & $0.015 \mathrm{~m}$ & $1281.5 \mathrm{Kg} / \mathrm{m}^{3}$ \\
\hline 9 & Density of bulk conveyed & $2403 \mathrm{Kg} / \mathrm{m}^{3}$ & 0.35 \\
\hline 10 & Friction coefficient at drive pulley & 0.352 & $240^{0}$ \\
\hline 11 & Angle of wrap at drive pulley & $220^{0}$ & $2.55 \mathrm{~m} / \mathrm{s}$ \\
\hline 12 & Speed of conveying & $2.55 \mathrm{~m} / \mathrm{s}$ & $1600 \mathrm{tph}$ \\
\hline 13 & Capacity of conveying & $3400 \mathrm{tph}$ & $170 \mathrm{KW}$ \\
\hline 14 & Tractive Power at drive pulley & $160 \mathrm{KW}$ & \\
\hline
\end{tabular}

\section{Results and Discussion}

\section{Case 1}

Horizontal belt conveyor system is used for lighter bulk load for comparatively less conveying distance than other inclined case. Figure 4 shows velocity variation of five belt segment varies rapidly in initial time period and then stable to designed speed of $2.55 \mathrm{~m} / \mathrm{s}$ after $80 \mathrm{~s}$. Transient variation in the speed is more in tail end segment of the conveyor belt and lesser variation as approaches to drive end. Time lag between velocity curves shows that stress wave progressively propagated from drive end towards tail end and variation is nonlinear. Displacement curves of 
International Journal of Mathematical, Engineering and Management Sciences

Vol. 4, No. 5, 1169-1179, 2019

https://dx.doi.org/10.33889/IJMEMS.2019.4.5-092

belt segments are shown in the Figure 5, which shows positive displacement for the carrying side during starting period whereas; returning side belt segment shows contraction for first $15 \mathrm{~s}$. Further it is seen that maximum difference in the displacement curve observed between $1^{\text {st }}$ and $2^{\text {nd }}$ belt segment, represents maximum belt elongation occurs in the carrying side. Variation in dislocation is significant during initial 50s and then after displacement curves progressed with constant difference for further steady state running.

Dislocation difference between successive belt segments are evaluated in terms of total belt elongation and shown in the Figure 6. it is observed that belt stretch during the transient condition reaches at maximum peaks of $17 \mathrm{~m}$. Magnitude of stretch fluctuate during system starting and settled at constant stretch value of $10 \mathrm{~m}$ for steady state running. Maximum value of belt stretch during operation decides stroke space for the take-up travel. In the straight horizontal belt conveyor of total belt length $1500 \mathrm{~m}$, maximum stretch in belt founds $1.13 \%$ and stretch for steady state running is $0.66 \%$ of total belt length.

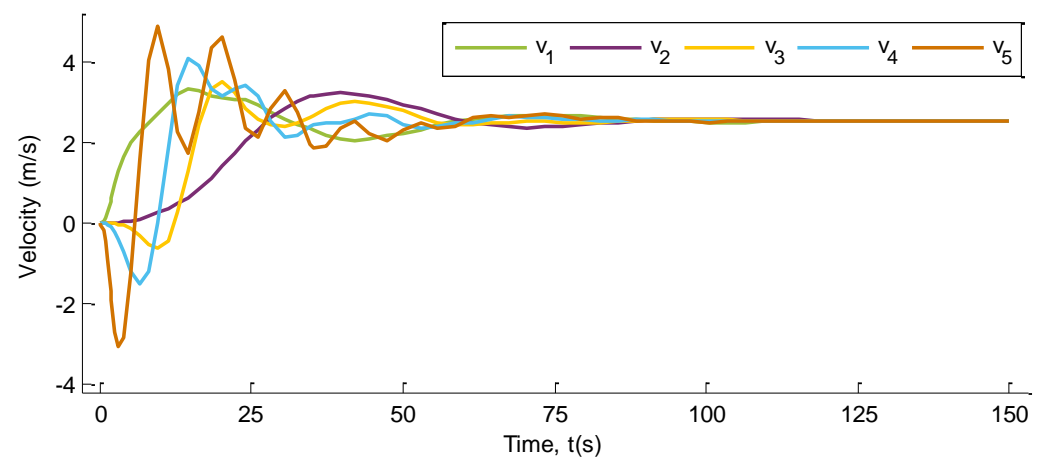

Figure 4. Velocity curves (Case 1)

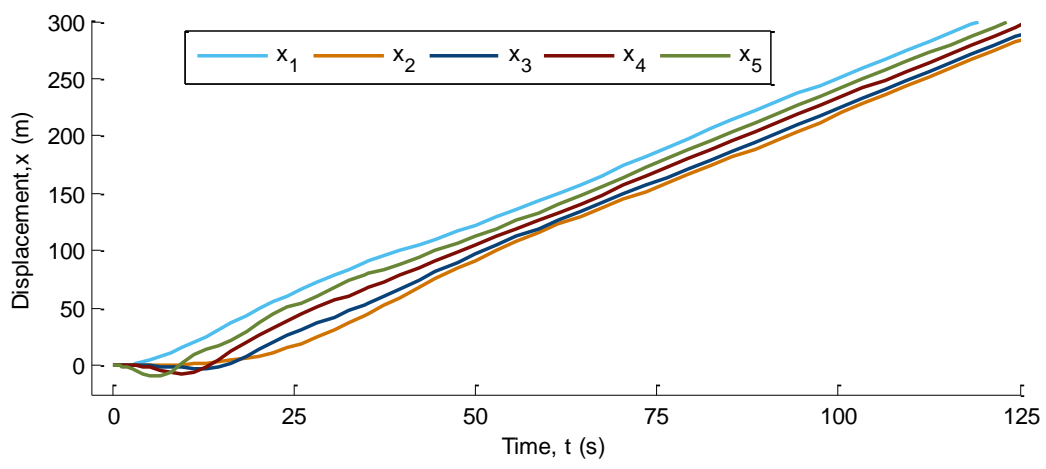

Figure 5. Displacement curves (Case 1) 
International Journal of Mathematical, Engineering and Management Sciences

Vol. 4, No. 5, 1169-1179, 2019

https://dx.doi.org/10.33889/IJMEMS.2019.4.5-092

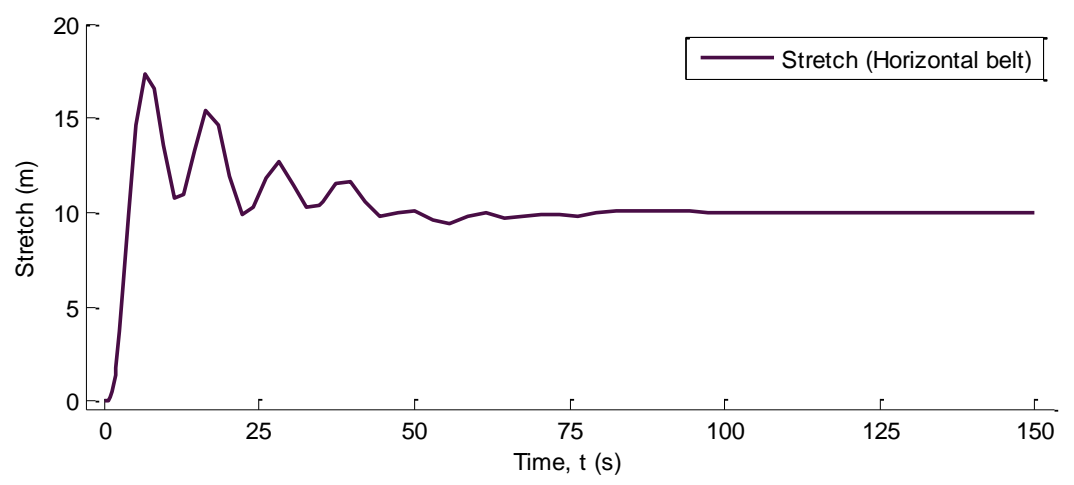

Figure 6. Belt stretch curve (Case 1)

\section{Case 2}

In case of inclined profile of belt conveyor chosen, velocity curves observed in Figure 7 are more vibrant than previous case due to incline gravitational motion of return side belts. In transient period velocity raised to higher value of $6.3 \mathrm{~m} / \mathrm{s}$ during initial $10 \mathrm{sec}$ signifies that straight inclined profile is less stable for belt running. In actual practice combination of horizontal and inclined profile preferred to achieve desire lift. Settling period for velocity curves also greater and reaches steady state of designed conveying velocity of $2.55 \mathrm{~m} / \mathrm{s}$ after 140 second. Belt stress also depends on equivalent linear moving mass, whose lower value in this case allows low strength fabric belt. Transient displacements of belt segments of conveyor belt are shown in Figure 8. Compare to straight conveyor, inclined conveyor shows more variation in between the adjacent nodes and these variations lasting for more time period also.

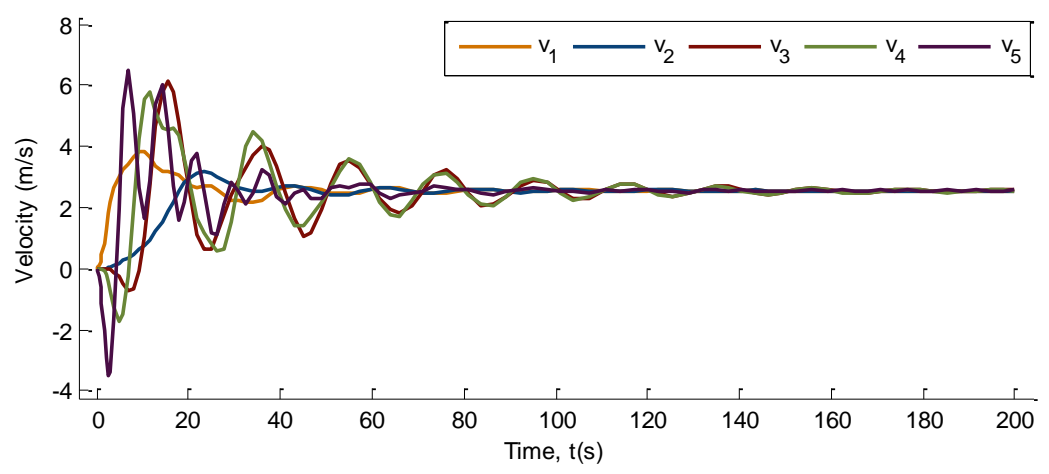

Figure 7. Velocity curves (Case 2) 
International Journal of Mathematical, Engineering and Management Sciences

Vol. 4, No. 5, 1169-1179, 2019

https://dx.doi.org/10.33889/IJMEMS.2019.4.5-092

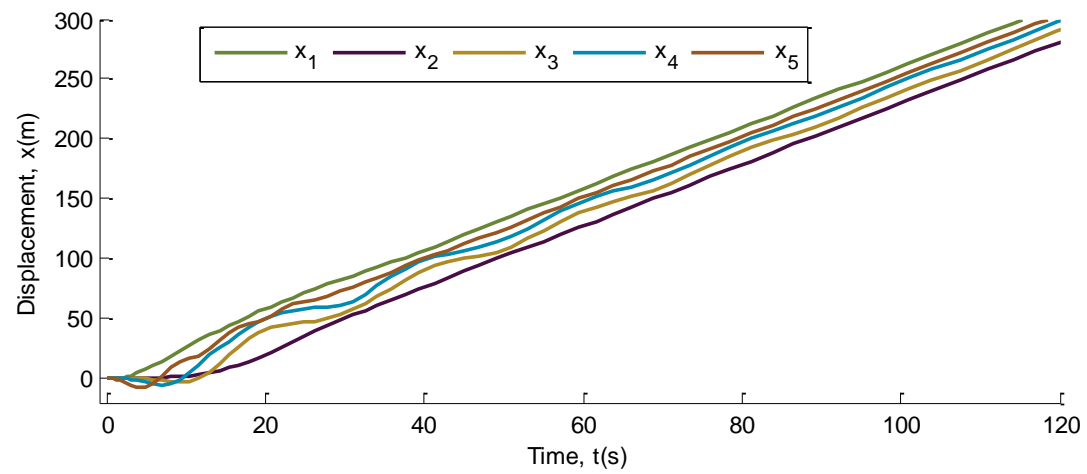

Figure 8. Displacement curves (Case 2)

More variations in displacement curves confirm more fluctuation in stretch value in the inclined belt system as observed in Figure 9. For belt tape length of $1250 \mathrm{~m}$ for straight inclined belt conveyor shows maximum stretch during full load starting as $1.16 \%$ and during steady state running condition as $0.64 \%$ of total belt length

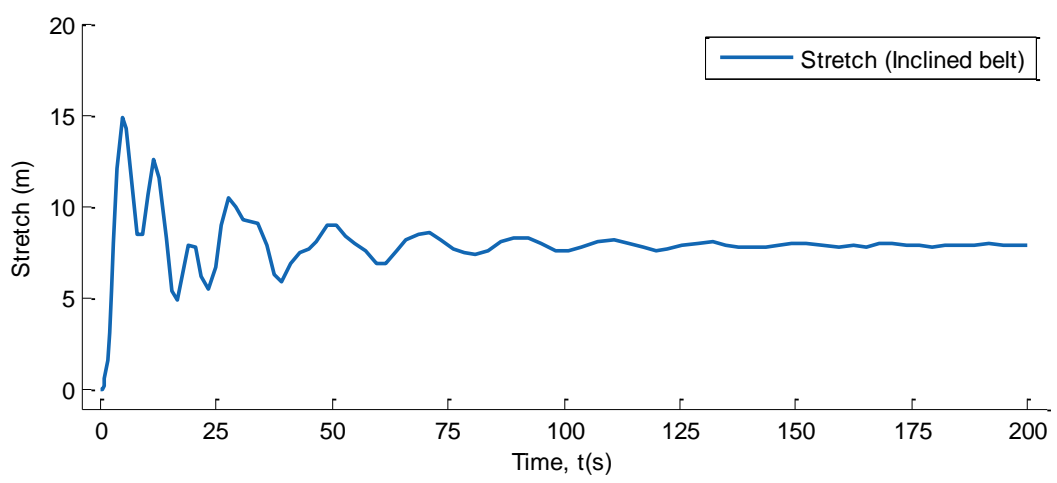

Figure 9. Belt stretch curve (Case 2)

\section{Conclusion}

Failure of conveyor belt during transient starting is often case that occurs in belt conveyor system. Simulation technique provides further real key explanation for dynamic system. Belt conveyor system is complex mechanical vibratory system. During fully loaded starting of system, dynamic belt stretch changes rapidly in transient period and settled at steady state value. Gravity take-up compensates this belt elongation by moving to and fro during operation. The stroke length of take-up usually adjusted for maximum $2 \%$ of belt elongation. The simulated result for the both cases comprises the standard value. Displacement curves signify more belt stretch near the drive pulley on carrying side, which put forward innovative method for starting stress calculation in the belt. In transient starting period movement of take-up will be faster for inclined belt system than 
International Journal of Mathematical, Engineering and Management Sciences

Vol. 4, No. 5, 1169-1179, 2019

https://dx.doi.org/10.33889/IJMEMS.2019.4.5-092

horizontal belt conveyor. Output figures helps to get better stability and lower down the safety factor for belt conveyor system. Proposed dynamic model can improve by considering more number of lump units on the belt. Physical specifications of conveying system also shows influence on the behavior of belt stretch, mathematical relationship would help to predict maximum belt stretch before installation of system.

\section{Conflict of Interest}

The author(s) confirm that this article contents have no conflict of interest.

\section{Acknowledgement}

We are grateful to all the reviewers for their encouraging comments and valuable corrections.

\section{References}

Alzoubi, M.F., Khateeb, S., \& Al-Hallaj, S. (2016). Modeling of compression curves of phase change graphite composites using Maxwell and Kelvin models. Journal of Composite Materials, 50(8), 11231135.

BIS. (2010). IS 11592: 2000 Selection and design of belt conveyors - code of practice. New Delhi, India: Bureau of Indian Standards.

CEMA, (1997). Belt conveyors for bulk materials, 5th Edition. USA: Conveyor Equipment Manufacturers Association.

DIN 22101: 2011-12. (2011), Continuous conveyors - belt conveyors for loose bulk materials - Basis for calculation and dimensioning. Berlin, Germany: DIN Deutsches Institut für Normung e. V.

Dunlop, (2016). Technical manual, conveyor belting, Version 2.6, Australia: Fenner Dunlop.

Harrison, A. (1998). Modeling belt tension around a drive drum. Bulk Solids Handling, 18(1), 75-80.

Harrison, A. (2008). Non-linear belt transient analysis - a hybrid model for numerical belt conveyor simulation. Bulk Solids Handling, 28(4), 242-247.

Hou, Y.F., \& Meng, Q.R. (2008). Dynamic characteristics of conveyor belts. Journal of China University of Mining and Technology, 18(4), 629-633.

Hu, K., Guo, Y.C., \& Wang, P.Y. (2010, June). Simulation methods for conveyor belt based on virtual prototyping. In 2010 International Conference on Mechanic Automation and Control Engineering (pp. 2332-2334). IEEE.

Jazar, R.N. (2013). Advanced vibrations: a modern approach. Springer Science \& Business Media.

Karolewski, B., \& Ligocki, P. (2014). Modelling of long belt conveyors. Maintenance and Reliability, 16(2), 179-187.

Kim, W.J., Park, T.G., \& Lee, S.S. (1995). Transient dynamic analysis of belt conveyor system using the lumped parameter method. Bulk Solids Handling, 15(4), 573-578.

Kulinowski, P. (2014). Simulation method of designing and selecting tensioning systems for mining belt conveyors. Archives of Mining Sciences, 59(1), 123-138.

Lakes, R. (2009). Viscoelastic materials. Cambridge University Press. ISBN: 9780521885683. 
International Journal of Mathematical, Engineering and Management Sciences

Vol. 4, No. 5, 1169-1179, 2019

https://dx.doi.org/10.33889/IJMEMS.2019.4.5-092

Leamy, M.J., \& Wasfy, T.M. (2002). Transient and steady-state dynamic finite element modeling of beltdrives. Journal of Dynamic Systems, Measurement, and Control, 124(4), 575-581.

Li, J., \& Pang X. (2018). Belt conveyor dynamic characteristics and influential factors. Shock and Vibration. Article ID 8106879, 13 pages. https://doi.org/10.1155/2018/8106879.

Lodewijks, G. (1996). Dynamics of belt systems. Ph.D thesis. Delft University of Technology, Delft, Netherland.

Manjgo, M., Piric, E., Vuherer, T., \& Burzic, M. (2018). Determination of mechanical properties of composite materials-the rubber conveyor belt with cartridges made of polyester and polyamide. Annals of the Faculty of Engineering Hunedoara, 16(1), 141-144.

Mulani, I.G. (2012). Engineering science and application design for belt conveyors. Madhu I. Mulani.

Nordell, L.K., \& Ciozda, Z.P. (1984). Transient belt stresses during starting and stopping: elastic response simulated by finite element methods. Bulk Solids Handling, 4(1), 93-98.

Pang, X., Li, J., \& Kou, Z. (2015). Longitudinal vibrations of the viscoelastic moving belt. Shock and Vibration. Article ID 769309, 6 pages. https://doi.org/10.1155/2015/769309.

Rao, S.S. (2007). Vibration of continuous systems. John Wiley \& Sons, Inc. ISBN: 978-0-471-77171-5.

Song, W., Wen, B., \& Liu, H. (2006). Simulation research on dynamics of belt conveyor system. International Design Engineering Technical Conferences and Computers and Information in Engineering Conference, Volume 2: $30^{\text {th }}$ Annual Mechanisms and Robotics Conference, Parts A and B, pp. 645-654, ASME. doi:10.1115/DETC2006-99024.

Woodcock, C.R., \& Mason, J.S. (2012). Bulk solids handling: an introduction to the practice and technology. Springer Science \& Business Media.

Yang, G. (2014). Dynamics analysis and modeling of rubber belt in large mine belt conveyors. Sensors \& Transducers, 181(10), 210-218. 